\title{
Malignant Gastrointestinal Stromal Tumor
}

National Cancer Institute

\section{Source}

National Cancer Institute. Malignant Gastrointestinal Stromal Tumor. NCI Thesaurus.

Code C53999.

A gastrointestinal stromal tumor that is characterized by large size (diameter greater than $10 \mathrm{~cm}$ for gastric localization and greater than $5 \mathrm{~cm}$ for intestinal localization) or more than 5 mitotic figures per 50 high power fields. 